European Journal of Communication

\section{Organised lying and professional legitimacy: Public relations' accountability in the disinformation debate}

(c) The Author(s) 2020
Article reuse guidelines: sagepub.com/journals-permissions DOI: |0.| |77/0267323|2096685 | journals.sagepub.com/home/ejc

(S)AGE

\author{
Lee Edwards \\ London School of Economics and Political Science, UK
}

\begin{abstract}
The role of the public relations industry in the disinformation debate has been largely overlooked, while an emphasis has been put on the responsibilities of platforms, media organisations and audiences to monitor content and eliminate fake news. In contrast, this article argues that disinformation and fake news are well-established tools in public relations work and are implicated in the current crisis. Drawing on an exploratory study of UK industry publications about fake news and disinformation, the article shows that public relations has addressed disinformation as a commercial opportunity and a platform for demonstrating professional legitimacy. Industry narratives position professional practice as ethical, trustworthy and true, while simultaneously 'othering' dubious practices and normalising 'organised lying'. The article concludes by arguing that the fight against disinformation must take seriously the impact of public relations, if it is to be effective.
\end{abstract}

\title{
Keywords
}

Disinformation, Hannah Arendt, organised lying, professional legitimacy, public relations

In academic and practitioner debates about disinformation and fake news, ${ }^{1}$ the main actors are generally cast as shadowy individuals or organisations, working to unseat democracy and outside the spectrum of ethically acceptable communication. This obscures the fact that 'organised lying' - the intentional, systemic dissemination of falsehoods by groups, organisations and institutions - has long been part of political life (Arendt, 1968), and the tools used to create and promote disinformation come directly

\footnotetext{
Corresponding author:

Lee Edwards, Department of Media and Communications, London School of Economics and Political Science, Houghton Street, London WC2A 2AE, UK.

Email: l.edwards2@Ise.ac.uk
} 
from the mainstream stable of promotional tactics, dating back to the days of propaganda and public opinion manipulation (Bernays, 2005 [1928]; Corner, 2007; Demetrious, 2019; Mayhew, 1997; Ong and Cabanes, 2018; Shir-Raz and Avraham, 2017). Lobbying and political communication have faced significant public and academic criticism (see, for example, Davis, 2002; Drutman, 2015; spinwatch.org) and in this article, I extend these arguments by exploring how the normalised nature of disinformation and fake news in mainstream professional communication has also contributed to the current problem.

Using the example of the UK public relations (PR) industry, I show how the construction of a shadowy 'other' (the 'bad' disinformation actor) in debates about fake news implies that visible, professional communication is 'good' communication, and allows the industry to sidestep responsibility for the current situation. Professional discourses divert attention from practices that are morally questionable, and instead legitimise professionalised communication as part of the solution to disinformation. The profession thereby deploys 'fake news' and 'disinformation' in order to protect its interests, but simultaneously damages the quality of political debate. I conclude by arguing that while PR, as a form of political action, has the potential to contribute to political life, this will only be possible if there is a fundamental, and public, re-examination of the inextricable links between truth, lying and politics in the profession, and a re-orientation towards democratic, rather than organisational ideals.

\section{Organised lying and contemporary disinformation}

The term 'organised lying' originates with Hannah Arendt's $(1968,1971)$ discussions of truth, lying and politics. In a political world driven by opinion formation about the meaning of things, she argues that facts, with their 'intractable, unreasonable stubbornness' (Arendt, 1968: 243), are potentially impotent in political debates because they can only reflect the world as it is. Lying, however - defined as the instrumental dissemination of information and/or opinion that has no basis in fact - is always a form of political agency. Lies can readily be used to promote a particular point of view or to encourage particular forms of action, because of their persuasive power: unconstrained by reality, 'the liar is free to fashion his "facts" to fit the profit and pleasure, or even the mere expectations, of his audience . . .' (Arendt, 1968: 251). Organised lying takes the impact of the lie further. More than obscuring some interpretations of the world, it actively destroys them in the service of 'a major and permanent adjustment or displacement of reality' (Arendt, 1971; Corner, 2007: 674). Such fundamental ontological work requires that these systematic distortions of reality are embedded in the ways in which politics is not only communicated, but also organised, in order that policymakers themselves believe the distortions. Thus, organised lying has the potential to replace concern for the common good in political debates with a concern for vested interests, while misrepresenting those interests to both the public and to policymakers as the common good.

The sophistication of organised lying in politics, using techniques borrowed from 'Madison Avenue' (Arendt, 1968, 1971), and the fact that such techniques are commonly used without sanction in non-political contexts - particularly in commercial sectors both normalises the practice and makes it difficult to detect and challenge. From this 
perspective, disinformation is part of the overarching system of organised lying that characterises contemporary political and economic life. As Harsin (2019) argues, 'Both consumer capitalism, deeply embedded in everyday life, and elite liberal democracy [. . .] demand deceptive communication. There is a structural incitement to deception' (np, emphasis added).

The normalisation of organised lying is reflected in current research on disinformation, which shows that audiences do not necessarily trust news outlets, regard 'real' news as flawed, and position 'fake' news on a continuum of news credibility, rather than in binary opposition to 'truth'. They assess the credibility of content based on a range of cues including the source, their familiarity with digital technologies, and their stance towards the issue in question (Coleman, 2012; Marchi, 2012; Nelson and Taneja, 2018; Nielsen and Graves, 2017; Shen et al., 2019; Tandoc et al., 2018b). Rather than being absolute, truth is what happens to news when it is taken up and assessed by audiences in the epistemically fragmented contemporary context (Waisbord, 2018), and lies may be taken to be true, under the right conditions. In a new twist to the contemporary dynamics of organised lying, this means that audiences may contribute to the scale and spread of disinformation by unwittingly sharing or promoting falsehoods on social media; relying on the 'collective intelligence' of the Internet to establish truth (Pantumsinchai, 2018); or equating popularity with credibility and circulating content without interrogating its origins.

If truth is always subject to interpretation, then organised lying may be perceived as simply generating some of many co-existing truths. Indeed, to claim one truth as definitive may be tantamount to totalitarian dictatorship, opening the door to violence and inequality (Mejia et al., 2018; Nelson, 1978). Yet, organised lying remains a concern because it interferes with our 'intersubjective judgement' (Coleman, 2018) - our capacity and freedom to see the world from multiple different perspectives. Intersubjective judgement is essential to pluralist politics and to public debate about collective issues, but is abused and perverted when mendacity is deployed in the service of power so that the perspectives available to us are manipulated or intentionally obscured (Arendt, 1968).

\section{Public relations and disinformation}

While Arendt associated organised lying with 'Madison Avenue' - a reference to the advertising industry - the PR industry might be regarded as a more potent source of lies in contemporary politics. Its political branches of practice - lobbying, public affairs and political communication - have all been extensively criticised for the negative impact they have on democratic processes because they foster networks of elites, facilitate undue influence on policymaking processes, and work to ensure politics serves corporate, rather than public interests (Davis, 2002; Drutman, 2015; Hamelink, 2007; Miller and Dinan, 2007; Miller and Harkin, 2010). However, the role of the industry more generally in the disinformation crisis has been largely overlooked, with an emphasis instead on the responsibilities of platforms, media organisations and audiences to monitor content so that fake news can be eliminated. Only in novel or extreme cases have PR companies been challenged as sources of fake news and disinformation (e.g. Alderman, 2017; Cox, 2017; Lapowsky, 2018). 
Some scholars have recognised the importance of mainstream promotional practices in the disinformation crisis. For example, Shu et al. (2017) argue that disinformation is a long-standing problem caused by producers' need to make a short-term profit and consumers' desire to satisfy their information needs. Bakir and McStay (2018) suggest that fake news is an exercise in optimising empathic appeals to audiences, a form of expertise in which advertisers excel. In their view, 'the history of fake news is a history of the influence of "professional persuaders", (Bakir and McStay, 2018: 157) who use promotion to realise economic interests, and for whom digital technologies offer more scope to extend their influence. They produce politicised content primarily because it secures 'eyeballs', clicks or other forms of online popularity that they can sell to advertisers (Allcott and Gentzkow, 2017; Tandoc et al., 2018a). The skilful construction of fake news as news; the integration of 'shareability' characteristics into appealing, emotive stories; the speed and scale of circulation; automated distribution through algorithms; and the echo chamber effect all exacerbate the impact of disinformation (Allcott and Gentzkow, 2017; Farkas et al., 2018; Harsin, 2019; Mustafaraj and Metaxas, 2017; Shu et al., 2017). Audiences are the goal and lying is permitted if it achieves visibility and attention. It is this promotional logic, which ignores integrity of content, that endangers the quality of political information and public debate and results in institutions with no regard for the quality of politics becoming an important influence on public discussions as they pursue their objectives.

When lying is done on such a scale, a fundamental destabilisation of the world is at stake. As Arendt (1968) argues,

[t] he result of a consistent and total substitution of lies for factual truth is [. . .] that the sense by which we take our bearings in the real world - and the category of truth vs falsehood is among the mental means to this end - is being destroyed. (p. 257)

Trust in truth-tellers becomes more fragile, and space opens up for claims not only to truth but also to truth-telling, in what Harsin (2015) has described as 'truth markets' (p. 328). In such circumstances, professions that claim communications expertise, such as PR, are well-placed to compete for territory and legitimacy as purveyors of truth. However, for PR at least, competing effectively requires both the profession and its audiences to overlook its historical and current practices of disinformation.

In fact, disinformation has a well-established pedigree across the PR industry, manifesting as intentional dissemination of incorrect information; hiding or maintaining silence about issues; and reframing issues in order to deflect debate and serve organisational interests. In the political sphere, for example, practitioners have worked for a wide range of questionable governments, fostering relations with other countries and populations by remaining silent about, or actively obscuring, undesirable realities such as human rights abuses or anti-democratic practices (Alderman, 2017; Bentele and Wehmeier, 2003; Davis, 1977; Heath et al., 2018; Mejias and Vokuev, 2017). Such accounts have been justified by arguing that they are trade-related rather than politically motivated; an arbitrary separation of economy and politics to deflect criticism (Davis, 1977; Heath et al., 2018; L'Etang, 2004). Within political systems, professional communicators have influenced the structure of political life and the quality of democracy by 
altering the 'practical work of politics' (Davis, 2002; Sheingate, 2016: 12) and enhancing corporate influence by presenting arguments in ways that serve their interests and marginalise alternative perspectives.

Research on the contemporary disinformation crisis shows that ethical concerns about professional communication strategies and tactics in politics remain rare. For example, Briant (2018) argues that the migration of propaganda tactics from wartime to peacetime communication has resulted in the growth of an 'influence industry' (p. 1) that remains poorly regulated, largely unscrutinised, and has facilitated the spread of disinformation. Ong and Cabanes (2018) have shown that the advertising and PR industries in the Philippines have expanded into the disinformation 'market' and created a fully fledged subcultural promotional industry. Mainstream practitioners take secondary employment as the country's disinformation 'architects', use standard promotional techniques (e.g. message development, using third-party influencers, deploying bots), and normalise their work as something that 'everyone' does. Deeply embedded in Filipino political culture, they 'hide in plain sight, wearing respectable faces, sidestepping accountability while the public's moral panics about trolling are directed elsewhere' (Ong and Cabanes, 2018: 3).

In commerce, disinformation has been a common tactic for communicating a positive view of corporations, securing legitimacy by obscuring the profit motive in favour of claims of social beneficence (Ewen, 1996; Marchand, 1998). Cutlip (1994) describes how one of the earliest US PR firms, the Southern Publicity Association, reframed the Klu Klux Klan's reputation as a legitimate organisation, paving the way for its revival in the 1920s. Hill and Knowlton worked for the Tobacco Research Council, a front group that actively distorted knowledge about the effects of smoking (Miller, 1999). Other contemporary examples include misleading or false communication by the pharmaceutical, food, alcohol, genetics and extractive industries (Aronczyk, 2018; Greenberg et al., 2011; Mickey, 2002; Miller and Harkin, 2010; Shir-Raz and Avraham, 2017; Weaver and Motion, 2002). The charity and non-governmental organisation (NGO) sectors are no exception to these practices, although they may not be as common. In recent years, global charity Oxfam has covered up sexual abuse by its staff in Haiti (O'Neill, 2018), while Médecins Sans Frontières was accused of a toxic culture where sexual harassment went unchallenged and reports were ignored (Adams, 2018).

It is important to note that PR's disinformation practices in both commercial and nonprofit sectors are a form of political action, given that the claims made (or silences maintained) are designed to influence the ways we 'take our bearings' in the world by limiting the range of subjectivities from which we might judge our own and others' position. As Marchand's (1998) extensive analysis shows, professional communicators have worked to integrate the corporate 'voice' into social debates since the mid-20th century, opening the door to influence in the political sphere: '[Corporate publicity's] omnipresence and political thrust have ensured corporate imagery a prominent role in public dialogue on family, class, community and politics' (Marchand, 1998: 362). Equally, non-profit communications challenge existing social, economic and/or political arrangements and promote values and beliefs for which they seek support (e.g. as donations or volunteer time). Given these realities, it seems reasonable to argue that the PR industry should be accountable for disinformation practices enacted not only by practitioners working in politics per 
se, but also by those in other sectors, because the latter are no less political, designed to change the relative power of civic, economic and political interests.

\section{Disinformation, professional interests and public accountability}

In practice, disinformation presents a professional dilemma for the PR industry, which means accountability may be difficult to achieve. The embeddedness of disinformation practices reveals that the industry has a professional stake in their survival; it is in its interests to protect the ability to produce disinformation, since it is a means of servicing client needs effectively. Practitioners have a contractual obligation to service clients (Kim and Ki, 2014) and disinformation can be part of the package (Jackson and Moloney, 2019). Client interests are fundamental to the industry's identity as a profession that manages reputation and risk; understands and engages with audiences in complex communications environments; and contributes to the client's bottom line (Edwards, 2014). Client-driven measures of PR's legitimacy dominate the disciplinary logic of the field, the 'network of accountability within which the professions have to inscribe their practice and expertise' (Fournier, 1999: 288). Industry codes of conduct also position the client relationship as the priority, while contributions to democracy, freedom of speech, the public interest, professional standards and practitioner integrity often remain vague and unenforceable (Fawkes, 2014; Kim and $\mathrm{Ki}, 2014) .{ }^{2}$ In other words, the 'network of accountability' in PR centres on the client, and disinformation can be justified insofar as it supports client interests.

However, professional legitimacy also requires evidence of an occupation working in the public interest (Abbott, 1988). This requirement means the industry should disown corruption, poor practice and illegality, in order to maintain its social standing and justify the financial and status rewards that its practitioners enjoy (Edwards, 2014; Fawkes, 2014; Pieczka and L'Etang, 2006). Given the negative associations of disinformation and fake news, such practices constitute a significant threat to PR's reputation. Should disinformation be taken to illustrate the inherently unethical nature of PR, its claim to legitimacy based on delivering a public service is severely weakened.

Herein lies the industry's dilemma: protecting disinformation is an ethical obligation to clients but a professional liability, while mitigating disinformation is an ethical liability in relation to clients, but a professional advantage. If disinformation and PR are talked about in the same breath there is a significant reputational risk of being branded as the cause of a disinformation-saturated, post-truth world, which raises unwelcome possibilities such as the potential for regulation, challenges to media relationships and access, and reduced trust. ${ }^{3}$ At the very least, debates about disinformation have the potential to make public an ethically suspect and self-interested aspect of practice that has been hitherto either ignored, or critiqued only on a case-by-case basis. From a professional perspective, PR must maintain its distance from disinformation in order to minimise the threat to legitimacy - but this presents a conundrum when disinformation is part of practice. To protect its legitimacy, the industry has to find a way to respond to the professional threat posed by disinformation without revealing its complicity. In essence, this is a requirement for political action in the sense that admitting the pure truth of disinformation as a significant challenge to democratic life is insufficient for the challenge. Rather, a mode of organised lying is required to realise professional self-interest. 


\section{Public relations in the disinformation debate}

To examine how the industry deals with this dilemma, an exploratory qualitative content analysis was conducted of UK-focused industry publications on fake news or disinformation, appearing online from November 2016 to December 2017. The publications were not taken to be a true reflection of what the industry actually does, but as an exercise in reputation management in the face of the professional challenge that disinformation presents. The focus was on the ways in which the industry articulated its position in relation to fake news and disinformation debates, and how that position functioned to protect its professional legitimacy. While general news coverage of PR and fake news critiques the industry based on high profile cases such as Cambridge Analytica or Bell Pottinger, the focus here was on how the industry constructs its professional identity in relation to external debates, and so industry-authored articles were appropriate for the sample.

The sample was sourced through general searches online using the terms 'fake news', 'disinformation', 'public relations' and by targeting specific organisations that had symbolic authority to 'speak' for the industry on the issue. There is no single regulatory authority or industry association for PR in the United Kingdom, so a range of organisations were included in this more specific targeting exercise: the UK industry associations (the Chartered Institute of Public Relations (CIPR) and the Public Relations Consultants' Association (PRCA)); the top 10 consultancies in the PRWeek UK top 150 2017; and key industry trade publications (PR Moment; PRWeek; Campaign; Communicate). Articles from other agencies and organisations were also included when they appeared in the searches: Cision, which provides a popular media monitoring service (Gorkana) to the PR industry, and consultancies that published commentaries about disinformation on their websites. The final data set comprised 42 texts: 38 were commentaries or opinion pieces, one was the PRCA's submission to the government consultation on fake news and three were research reports issued by consultancies (Instinctif partners, Cision and Lewis PR). The publications were concentrated in the first half of the sampling timeframe, which is when the fake news debate in the United Kingdom was most vociferous.

Texts were entered into NVivo for iterative thematic coding. First the texts were read closely, to gauge the overall argument being made in each one. Next, individual themes were identified that related to the nature of fake news and disinformation, and the role of $\mathrm{PR}$ in relation to the production, dissemination or resolution of the disinformation/fake news problem. Themes included the context (e.g. changing media landscape, political context), characteristics (e.g. speed of dissemination, fictional content), challenges presented by fake news/disinformation (e.g. to democracy, to brands), audience responsibilities (e.g. for fact-checking, verifying news) and PR's role (e.g. as a source of facts, skills or protector of reputation). Finally, patterns were identified that occurred across the texts and suggested the emergence of an overarching industry narrative. These were the causes of fake news/disinformation, disinformation as a promotional opportunity and PR as a source of truth and trust.

\section{Findings}

The profession's response to the disinformation crisis is located in a world where fake news threatens organisations trying to communicate in good faith. It spreads fast and is 
large-scale. It ranges from outright lies to poor journalism resulting in unintentional misinformation, and its cause is the new media context, with the networked environment, multiple sources, algorithms and echo chambers all presenting problems for communicators.

\section{Causes and consequences of the crisis}

Many texts provide an overview of the causes and consequences of the fake news and disinformation crisis. Causes are attributed to other parties, while consequences are presented as risks to clients and brands. Disinformation producers are presented as market actors, devoid of political interest and motivated only by profit. For example, Cision Gorkana, in 'PR can fight fake news', states, '[T]he motivation for publishing fake news isn't ideological - fake news can be a lucrative endeavor for many publishers'. Causes are also located in audience behaviour, because they are critically disengaged, passive consumers of news, or simply seduced by social media to follow their own confirmation biases. In the following excerpt, the audience problem is presented as universal issue, a 'truth' about all of 'us', but driven by a context in which seemingly credible information is too widely available and too easily believed:

This easy access to 'facts' has the potential to instil in us a kind of intellectual arrogance. We might not know the answer to every question, but we are comforted by our certainty that we can simply look it up online. We are also confident that we can successfully navigate the 'facts' we surface online and parse what is 'fake' and what real. Unfortunately it's this very confidence that makes us susceptible to fake news. (Hill+Knowlton, The Disinformation Era)

In line with these causes, the texts avoid critiquing disinformation practices, and instead focus solutions on changing audience behaviour and regulating the platforms whose infrastructures allow disinformation producers to circulate fake news. The overconfident audience is called out to become more active, engage more critically with news and be more 'responsible'. To facilitate this, there should be adequate education on fake news:

Educating the public is equally important in combatting fake news as users on social media should be equipped with the tools and knowledge to distinguish between fake and legitimate news. (PRCA, Response to fake news inquiry)

In turn, regulators are urged to focus on platforms rather than promotional industries: 'The rise of online publishers requires new forms of industry regulation by technology companies' (PRCA, Response to fake news inquiry).

\section{Disinformation and fake news as a promotional opportunity}

Presenting fake news and disinformation as caused by corrupt communicators and audience (mis)behaviour allows the industry to position itself, in contrast, as a source of ethical communications expertise. Responding implicitly to the legitimacy threat, the texts frame disinformation as an opportunity to demonstrate professionalism by improving ethical conduct. An ethical binary is constructed between 'good' PR based on ethical and 
honest communication that can protect brands, and 'bad', unethical practice that is 'othered' because it undermines professional claims of delivering 'strategic value'. Legitimate practitioners need no additional regulation; they must simply raise the profile of their 'good' practice by highlighting their ethics more effectively:

As public relations professionals, our ability to deliver strategic value is dependent on honest and truthful communication. Fake news poses a threat to that process and for that reason we must elevate the importance of ethics in our day-to-day roles. (CIPR, CIPR welcomes fake news enquiry)

The threat of disinformation is represented as a challenge to organisations, rather than to the quality of democracy or public life, reflecting the client imperative that drives the industry. This opens up opportunities to frame disinformation as a business opportunity, a platform for the industry to reinforce its value as a service that can help organisations respond to environmental risks:

While 2016 saw much discussion of political fake news, in future businesses will also be the subject of aggressive campaigns based on misinformation. The need for intensive social media monitoring, rapid rebuttal, flexibility and empowerment of frontline communicators has never been greater. (CC Group, Fake news is a PR opportunity)

By framing disinformation in this way, PR is positioned as a solution to the disinformation crisis, not part of the problem. The industry's claim to strategic communications expertise and ethical leadership is further enhanced by highlighting professional skills such as monitoring and understanding audiences and the communications environment, creating relationships based on mutual trust, fact-checking on behalf of clients and advising on responses to fake news that will minimise reputational damage. Many publications included a sales pitch for services such as check lists, or advisories such as best practice tips about how to deal with the threat of fake news:

We each have a responsibility to independently verify data and check information before we quote it, share it and spread it further. Our fake news fact-checking checklist details the six steps you should take to verify if the story you're reading is legit, or not. (Signal Media, Fake News blog)

Where fake news has the potential to impact a company or brand's reputation, however, ensuring an effective and relevant crisis communications strategy is in place should be a priority for media and public relations professionals. (Communicate, Unspooling Spin)

\section{Public relations as a locus of truth and trust}

The culmination of 'othering' the causes of disinformation, locating the consequences within the remit of PR's professional territory, and framing solutions as PR expertise, is the broader claim that PR is a source of trusted content in a world of uncertainty. Both the media, under pressure to cut corners and at the mercy of corrupt sources, and the unwitting consumer seeking out trustworthy brands, can trust PR practitioners to deliver 
truthful content, while clients can call on practitioners to protect reputation in a risky world. These arguments create a closed loop logic that protects the industry from any association with disinformation. If PR practitioners are in the business of protecting their clients and supporting journalists, then they are by definition anti-fake news and do not engage in disinformation. Truth is central to the claim: PR is presented as a harbinger of truth, and able to distinguish between truth and mendacity. Truth and trust are linked in this 'truth market' (Harsin, 2015); as a source of truth, practitioners can also foster the trust - between brands and audiences, clients and practitioners, journalists and sources on which their legitimacy depends.

Equating the industry with trust and truth enhances the credibility of claims that its self-regulation controls reprehensible behaviour. Texts targeted at policymakers claim that regulation should be light rather than constraining, protecting freedom of speech and information - the latter being a crucial condition for the survival of PR (Byrum, 2017):

$[C]$ odes of conduct have clear regulations in the importance of the dissemination of accurate news to the media and public. [. . .] We must make a commitment to preserve freedom of speech. Policies and regulation that focus on fake news should not be an exercise in curbing freedom of speech. (PRCA, Response to fake news inquiry)

Taken together, these arguments provide a series of rebuttals to the professional challenges presented by disinformation, but fail to engage with the threat that disinformation poses to the quality of public life, or with the fact that disinformation techniques are also found in 'legitimate' PR practice. Truth, trust and credibility - the concerns that underpin the public debate about disinformation - are instrumentalised in the service of clients and the PR industry. Social, cultural and political issues beyond brand/client/professional interests are ignored. There is no discussion of the ways in which fake news and disinformation may distort public debate, no recognition of the fragility of practitioner ethics in practice and no critical, reflexive engagement with PR's history and contemporary role in the creation and circulation of fake news and disinformation. More positive reflection on how PR might actively foster democratic engagement is also absent.

\section{Discussion}

This analysis is an exploratory exercise, limited to one country, but it suggests the ways in which the PR industry uses disinformation and fake news in its struggles for professional legitimacy by constructing their meaning in ways that protect professional interests. The strategy unfolds as follows: disinformation exemplifies the environmental risks that PR protects against, and thereby provides a platform to demonstrate strategic leadership; it represents a new threat to clients, and simultaneously offers new territory for PR to occupy; and disinformation producers represent the unethical 'other', and therefore, provide a foil for demonstrating ethics and integrity. In other words, and in an ironic discursive twist, the 'othering' of disinformation simultaneously allows it to be incorporated into the profession as part of its raison d'être, transformed from being a threat to democracy built on flawed technological and media systems, to being a platform for the profession's economic and ideological interests. 
This discursive strategy has important advantages for professional legitimacy. First, it leaves PR's quotidian use of disinformation unscrutinised, because it is ethical by virtue of being carried out by 'good' practitioners, custodians of truth and trust. Second, it leaves open the option to ostracise practitioners whose dealings in disinformation become too visible. They can be readily framed as aberrant, corrupt and unrepresentative (see, for example, Public Relations Consultants Association, 2017), in order to protect professional legitimacy in the public arena. Third, framing fake news and disinformation as an organisational issue helps to obscure its deeply political effects. As Ong and Cabanes (2018) argue, the use of disinformation by practitioners does not attract critique because its practices have become normalised. Journalistic critiques of promotion tend to address client organisations, not PR practices, and this lack of scrutiny only facilitates the profession's 'disappearing act' from the disinformation debate.

Beyond the professional context, what are the implications of this work for the political sphere? There is a clear need to rehabilitate truth in politics as a basis for preserving the freedom to act, rather than imposing a singular reality, given that 'no viable freedom, speech, action or politics can survive without some sort of concern and room for matters of truth, properly conceived' (Nelson, 1978: 287). Rather than rehabilitate 'the conceit of objectivity' (Coleman, 2018: 159), the priority must be to preserve imagination and 'intersubjective judgement'. PR's use of disinformation clearly undermines the conditions for truth that can facilitate this kind of judgement, because it imposes 'another reality' (Arendt, 1968: 254) that divorces us from the political sphere and positions us only in relation to organisational interests. Only in an organisation-centric world can PR both frame and justify its organisational advocacy as truth-telling for journalists and consumers, and thereby claim legitimacy. In the process, our lives as citizens entitled to knowledge that facilitates political action and to relationships that can illuminate our judgement, are obscured.

Where does this leave the potential for politics in a PR-driven world of disinformation? Are we to be inevitably subjected to the 'Madison Avenue' tactics that so greatly concerned Arendt nearly half a century ago? Is there any escape, given the political power of PR discourse in all sectors, not only formal politics? Answers to such questions lie in how we make sense of the alignments, tensions and contradictions between truth, lying and politics (Nelson, 1978). For the PR profession, such sense-making must be grounded in recognition of its fundamental political potential as a discursive intervention in public life. As Nelson (1978) notes, '[s]peech enables the discourse and inquiry, as well as the public debate, which can move us together from our initial inclinations to our ultimate choices' (p. 293). However, taking this political potential seriously requires a rehabilitation of the incontrovertible, widely documented evidence of the profession's past and present lying into professional identity. This will, in turn, prompt questions of how to define 'truth', when and where communicating truth wins out over lying, and what conditions for political action may facilitate truth in PR practice, rather than mendacity.

Such debates should not be limited to the professional audience, because they require an ontological change in PR's claims to legitimacy, a move away from the organisationcentric world with which it currently identifies towards a recognition of the collective life it facilitates. PR is a powerful global industry with enormous consequences for our 
collective futures (Edwards, 2018). Greater public scrutiny of the detailed reality of PR practices is therefore necessary, including more forensic examination of the types of disinformation included in 'legitimate' work. Any discussion about lying, truth and PR should be political and public, rather than professional and private. At the very least, the language and practices of democracy must be integrated into professional consciousness. Only then can its responsibility for organised lying, and its political consequences, be effectively addressed.

\section{Funding}

The author(s) received no financial support for the research, authorship and/or publication of this article.

\section{ORCID iD}

Lee Edwards (iD https://orcid.org/0000-0001-6542-1234

\section{Notes}

1. Disinformation describes the circulation of intentionally misleading information for a specific purpose (Bennett and Livingston, 2018; Fetzer, 2004). Satire and parody are excluded, since their intention is to ridicule the truth rather than to mislead people in believing an alternative scenario. Fake news is one form of disinformation that can be detected through its facticity (the degree to which facts in a story are true or false) and intention (level of intent to mislead audiences). Of course, these two criteria may be difficult to assess in the context of skilfully created stories that combine fact with interpretation and are designed to misappropriate the credibility of mainstream news (Jack, 2017; Tandoc et al., 2018a).

2. The Institute of Public Relations (IPR; now Chartered Institute of Public Relations (CIPR)) only introduced its first code of conduct in the 1960s; its updated versions remain largely internally focused, with the public interest a marginal topic (Fawkes, 2014).

3. Without trust from audiences or clients, PR work will be inadequately resourced, and poorly disseminated. Taken to its extreme, a breakdown in trust means that PR will have nothing left to 'sell'.

\section{References}

Abbott A (1988) The System of Professions: An Essay on the Division of Expert Labour. Chicago, IL: University of Chicago Press.

Adams A (2018) Medecins San Frontieres Staff 'Used Local Prostitutes'. London: BBC News. Available at: https://www.bbc.com/news/world-africa-44523086.

Alderman L (2017) Bell Pottinger, British P.R. Firm for Questionable Clients, Collapses. New York: The New York Times.

Allcott H and Gentzkow M (2017) Social Media and Fake News in the 2016 Election. Cambridge, MA: The National Bureau of Economic Research.

Arendt H (1968) Truth and politics. In: Arendt H (ed.) Between Past and Future. New York: Penguin, pp. 223-259.

Arendt H (1971) Lying in Politics: Reflections on the Pentagon Papers. New York: The New York Review of Books.

Aronczyk M (2018) Public relations, issue management, and the transformation of American environmentalism, 1948-1992. Enterprise \& Society 19: 836-863. 
Bakir V and McStay A (2018) Fake news and the economy of emotions. Digital Journalism 6(2): $154-175$.

Bennett WL and Livingston S (2018) The disinformation order: Disruptive communication and the decline of democratic institutions. European Journal of Communication 33: 122-139.

Bentele G and Wehmeier S (2003) From literary bureaus to a modern profession: The development and current structure of public relations in Germany. In: Sriramesh K and Vercic D (eds) The Global Public Relations Handbook: Theory, Research and Practice. Mahwah, NJ: Lawrence Erlbaum, pp. 199-221.

Bernays E (2005 [1928]) Propaganda. New York: Ig Publishing.

Briant E (2018) Building a Stronger and More Secure Democracy in a Digital Age: A Response to Recent Interim Reports and Proposals on Fake News. London: U.K. Parliament Digital, Culture, Media and Sport Select Committee Inquiry into Fake News.

Byrum K (2017) The European right to be forgotten: A challenge to the United States constitution's first amendment and to professional public relations ethics. Public Relations Review 43: $102-111$.

Coleman S (2012) Believing the news: From sinking trust to atrophied efficacy. European Journal of Communication 27(1): 35-45.

Coleman S (2018) The elusiveness of political truth: From the conceit of objectivity to intersubjective judgement. European Journal of Communication 33(2): 157-171.

Corner J (2007) Mediated politics, promotional culture and the idea of 'propaganda'. Media, Culture \& Society 29(4): 669-677.

Cox J (2017) UK PR giant Bell Pottinger sacks partner and apologises for South African campaign accused of fuelling racism. The Independent. Available at: https://www.independent.co.uk/ news/business/news/bell-pottinger-south-africa-campaign-racial-tensions-apology-uk-prgiant-sacks-partner-a7828221.html.

Cutlip S (1994) Public Relations: The Unseen Power. Hillsdale, NJ: Lawrence Erlbaum Associates.

Davis A (2002) Public Relations Democracy: Public Relations, Politics and the Mass Media in Britain. Manchester: Manchester University Press.

Davis M (1977) Interpreters for Nigeria: The Third World and International Public Relations. Urbana, IL: University of Illinois Press.

Demetrious K (2019) 'Energy Wars': Global PR and public debate in the 21st century. Public Relations Inquiry 8(1): 7-22.

Drutman L (2015) The Business of America Is Lobbying: How Corporations Became Politicized and Politics Became More Corporate. New York: Oxford University Press.

Edwards L (2014) Power, Diversity and Public Relations. London: Routledge.

Edwards L (2018) Understanding Public Relations: Theory, Culture and Society. London: SAGE.

Ewen S (1996) PR! A Social History of Spin. New York: Basic Books.

Farkas et al. (2018). Cloaked Facebook pages: Exploring fake Islamist propaganda in social media. New Media \& Society 20(5): 1850-1867

Fawkes J (2014) Public Relations Ethics and Professionalism: The Shadow of Excellence. London: Routledge.

Fetzer J (2004) Disinformation: The use of false information. Minds and Machines 14(2): 231-240.

Fournier V (1999) The appeal to 'professionalism' as a disciplinary mechanism. The Sociological Review 47(2): 280-307.

Greenberg J, Knight G and Westersund E (2011) Spinning climate change: Corporate and NGO public relations strategies in Canada and the United States. International Communication Gazette 73(1-2): 65-82.

Hamelink C (2007) The professionalization of political communication: Democracy at stake? In: Negrine R, Holtz-Bacha R and Mancini P (eds) The Professionalization of Political Communication. Bristol: Intellect, pp. 179-187. 
Harsin J (2019) Post-truth and critical communication. In: Cloud D (ed.) Oxford Encyclopedia of Communication \& Critical Studies. New York: Oxford University Press. Available at: https:// oxfordre.com/communication/view/10.1093/acrefore/9780190228613.001.0001/acrefore9780190228613-e-757?rskey=GIsDq1\&result=12.

Harsin J (2015). Regimes of post-truth, post-politics, and attention economies. Communication, Culture \& Critique 8(2): 327-333.

Heath R, Schaart E and Kaleta P (2018) Saudi Arabia, the PR client no-one wants to talk about. Available at: https://www.politico.eu/article/saudi-arabia-the-pr-client-no-one-wants-to-talkabout/.

Jack C (2017) Lexicon of Lies: Terms for Problematic Information. New York: Data \& Society Research Institute.

Jackson D and Moloney K (2019) Uneasy lies the head that wears a crown. A qualitative study of ethical PR practice in the United Kingdom. Public Relations Inquiry 8(1): 87-101.

Kim SY and Ki EJ (2014) An exploratory study of ethics codes of professional public relations associations: Proposing modified universal codes of ethics in public relations. Journal of Mass Media Ethics 29(4): 238-257.

Lapowsky I (2018) Cambridge analytica took 50M Facebook users' data - and both companies owe some answers. Wired. Available at: wired.com/story/cambridge-analytica-50m-facebook-users-data/.

L'Etang J (2004) Public Relations in Britain: A History of Professional Practice in the 20th Century. Mahwah, NJ: Lawrence Erlbaum Associates.

Marchand R (1998) Creating the Corporate Soul: The Rise of Public Relations and Corporate Imagery in American Big Business. Berkeley, CA: University of California Press.

Marchi R (2012) With Facebook, blogs, and fake news, teens reject journalistic 'objectivity'. Journal of Communication Inquiry 36(3): 246-262.

Mayhew L (1997) The New Public: Professional Communication and the Means of Social Influence. Cambridge: Cambridge University Press.

Mejia R, Beckermann K and Sullivan C (2018) White lies: A racial history of the (post)truth. Communication and Critical/Cultural Studies 15: 109-126.

Mejias U and Vokuev N (2017) Disinformation and the media: The case of Russia and Ukraine. Media, Culture \& Society 39(7): 1027-1042.

Mickey T (2002) Deconstructing Public Relations: Public Relations Criticism. Mahwah, NJ: Lawrence Erlbaum Associates.

Miller D and Dinan W (2007) A Century of Spin: How Public Relations Became the Cutting Edge of Corporate Power. London: Pluto Press.

Miller D and Harkins C (2010) Corporate strategy, corporate capture: Food and alcohol industry lobbying and public health. Critical Social Policy 30(4): 564-589.

Miller K (1999) The Voice of Business: Hill \& Knowlton and Postwar Public Relations. Chapel Hill, NC: University of North Carolina Press.

Mustafaraj E and Metaxas P (2017) The fake news spreading plague: Was it preventable? In: WebSci'17: Proceedings of the 2017 ACM on web science conference. Troy, NY: Association for Computing Machinery, pp. 235-239. Available at: https://dl.acm.org/ doi/10.1145/3091478.3091523.

Nelson J (1978) Politics and truth: Arendt's problematic. American Journal of Political Science 22(2): 270-301.

Nelson J and Taneja H (2018) The small, disloyal fake news audience: The role of audience availability in fake news consumption. New Media \& Society 20(10): 3720-3737.

Nielsen R and Graves L (2017) 'News You Don't Believe': Audience Perspectives on Fake News. Oxford: Reuters Institute for the Study of Journalism. 
O'Neill S (2018) Minister Orders Oxfam to Hand Over Files on Haiti Prostitute Scandal. London: The Times. Available at: https://www.thetimes.co.uk/article/top-oxfam-staff-paid-haiti-quakesurvivors-for-sex-mhm6mpmgw.

Ong J and Cabanes J (2018) Architects of Networked Disinformation: Behind the Scenes of Troll Accounts and Fake News Production in the Philippines. London: Newton Tech4Dev Network.

Pantumsinchai P (2018) Armchair detectives and the social construction of falsehoods: An actornetwork approach. Information, Communication \& Society 21(5): 761-778.

Pieczka M and L'Etang J (2006) Public relations and the question of professionalism. In: L'Etang J and Pieczka M (eds) Public Relations: Critical Debates and Contemporary Practice. Mahwah, NJ: Lawrence Erlbaum Associates, pp. 265-287.

Public Relations Consultants Association (2017) Bell Pottinger case study. Available at: https:// www.prca.org.uk/campaigns/ethics/bell-pottinger-case-study.

Sheingate A (2016) Building a Business of Politics. New York: Oxford University Press.

Shen C, Kasra M, Pan W, et al. (2019) Fake images: The effects of source, intermediary, and digital media literacy on contextual assessment of image credibility online. New Media \& Society 21: 438-463.

Shir-Raz Y and Avraham E (2017) 'Under the Regulation Radar': PR strategies of pharmaceutical companies in countries where direct advertising of prescription drugs is banned - The Israeli case. Public Relations Review 43: 382-391.

Shu K, Sliva A, Wang S, et al. (2017) Fake news detection on social media: A data mining perspective. SIGKDD Explorations 19: 22-36.

Tambini D (2017) 'Fake News: Public Policy Responses'. Media Policy Brief 20. London: Media Policy Project, London School of Economics and Political Science.

Tandoc E Jr, Lim ZW and Ling R (2018a) Defining 'Fake News'. Digital Journalism 6(2): 137-153.

Tandoc E Jr, Ling R and Westlund O (2018b) Audiences' acts of authentication in the age of fake news: A conceptual framework. New Media \& Society 20(8): 2745-2763.

Waisbord S (2018) Truth is what happens to news: On journalism, fake news and post-truth. Journalism Studies 19(13): 1866-1878.

Weaver CK and Motion J (2002) Sabotage and subterfuge: Public relations, democracy and genetic engineering in New Zealand. Media, Culture and Society 24(3): 325-343. 